\title{
Study and Analysis of Rectangular Microstrip Patch Array Antenna at 28GHz for 5 G Applications
}

\author{
MOHAMED F. ABDULMAJID \\ Department of Communication College of Electronic \\ Technology Bani-Walid, LIBYA
}

\begin{abstract}
Fifth generation (5G) is the next major phase of mobile telecommunications standards beyond the current $4 \mathrm{G}$, which will operate at millimeter-wave frequency band. In any wireless device, the performance of radio communications depends on the design of an efficient antenna. This paper presents designs for rectangular microstrip antennas (single element, two elements, four elements and eight elements at $28 \mathrm{GHz}$ ), where $28 \mathrm{GHz}$ is one of the standard frequencies of the $5 \mathrm{G}$ communications. For better impedance matching, corporate feeding network is used in array configuration. Microstrip line and patch are etched on RT Duroid 5880 (dielectric constant of 2.2 and a height of $0.5 \mathrm{~mm}$ ) substrate material. Array antenna improves various performance parameters, namely, return loss characteristics, impedance bandwidth, gain, directivity, and radiation pattern. It is observed an improvement in most parameters. From the simulation results of eight elements array configuration, it is increased of $95.15 \%$ gain and directivity as compared to a single element configuration. It is also noticed that there is an increase of $148.54 \%$ in impedance bandwidth as compared to a single element configuration. There is decreased of beamwidth in $52.06 \%$ as compared to a single element. Thus, proposed eight elements microstrip patch array with modified corporate feeding is effective candidate for future $5 \mathrm{G}$ applications.
\end{abstract}

Keywords-Microstrip Patch Antenna, Array Antenna, Corporate feed Array, HFSS, 5G, 28 GHz.

Received: September 14, 2020. Revised: December 12, 2020. Accepted: January 6, 2021. Published: January 31, 2021.

\section{Introduction}

5th Generation is considered as beyond 2020 mobile communications. These standards are developed to serve the current and future demands of the mobile users. But, the mobile traffic worldwide is increasing exponentially each year and the trend will likely continue for the expected future. In recent years, numerous research foundations and industry partners have been researching the concept of a 5th generation $(5 \mathrm{G})$ mobile network improvements in capacity, latency, and mobility [1], [8]. Due to spectrum shortage in the conventional microwave bands, millimeter wave (mmWave) bands have been attracting great attention as an additional spectrum band for $5 \mathrm{G}$ cellular networks. Moving to the mm-Wave frequencies for $5 \mathrm{G}$ mobile stations requires new techniques in the design of antennas for mobile-station (MS) and base-station (BS) systems.

In order to achieve an efficient beam-steerable phased array antenna, which is one of the most important parts for $5 \mathrm{G}$ cellular systems, the smaller antennas arranged as an array can be employed.The number of devices could reach the tens or even hundreds of billions by the time $5 \mathrm{G}$ comes to fruition, due to many new applications beyond personal communications. Bearing in mind the above considerations, microstrip array antennas with corporate feeding technique are discussed in this study. All these antennas are targeted to operate at a $28 \mathrm{GHz}$ frequency band and produce end-fire radiation pattern for $5 \mathrm{G}$ communication [2]. Microstrip patch antenna has the advantages of simple to manufacture or fabricate, low cost, easy to form a large array and has light weight. However, it has some setbacks such as low gain and low bandwidth, but can be compensated using a thick substrate with low dielectric constants [3].

\section{Single Element Design}

There are many shapes for microstrip patch antenna such as circular, square, elliptical, rectangular...etc. Here, the rectangular type was used for its simplicity and popularity. As there are four different types to feed single patch element antenna, they are edge feed with quarter wave transformer, inset feed, probe feed with a gap, aperture coupled feed, edge feed with gap and two layer feed. In this study, edge feed with quarter wave transformer was applied [4], [6].

For the designing of microstrip patch antenna, dielectric substrate and resonate frequency first must be chosen. Parameters of Antenna can be find out by the equations are described below, to find width of patch $(\mathrm{W})$ :

$$
W=\frac{c}{2 f_{r}} \sqrt{\frac{2}{\varepsilon_{r}+1}}
$$

Where $\mathrm{W}=$ width of patch, $f_{r}=$ resonate frequency, $\mathrm{c}=$ free space velocity, $\varepsilon_{r}=$ dielectric constant of substrate.

Effective dielectric constant $\left(\varepsilon_{\text {reff }}\right)$ is given as:

$$
\varepsilon_{\text {reff }}=\frac{\varepsilon_{r}+1}{2}+\frac{\varepsilon_{r}-1}{2 \sqrt{1+12 \frac{h}{w}}}
$$

Where $\varepsilon_{\text {reff }}=$ effective dielectric constant, $\mathrm{h}=$ height of dielectric substrate [5], [7].

Length extension $(\Delta \mathrm{L})$ of patch is:

$$
\frac{\Delta L}{h}=0.412 \frac{\left(\varepsilon_{r e f f}+0.3\right)\left(\frac{w}{h}+0.264\right)}{\left(\varepsilon_{r e f f}-0.258\right)\left(\frac{w}{h}+0.8\right)}
$$

The actual length (L) is given as:

$$
L=\frac{c}{2 f_{r} \sqrt{\varepsilon_{r}}}-2 \Delta L
$$

Here desired resonate frequency is $28 \mathrm{GHz}$, dielectric constant of substrate (RT Duroid 5880) is 2.2 and height of the substrate is $0.5 \mathrm{~mm}$.

The characteristic impedance $\left(Z_{0}=50 \Omega\right)$, so it can be calculated width of feed line $\left(W_{2}\right)$ as follows:

$$
\begin{gathered}
B=\frac{377 \pi}{2 Z_{0} \sqrt{\varepsilon_{r}}} \\
\frac{W_{2}}{h}=\frac{2}{\pi}\left\{B-1-\ln (2 B-1)+\frac{\varepsilon_{r}-1}{2 \varepsilon_{r}}\left[\ln (B-1)+0.39-\frac{0.61}{\varepsilon_{r}}\right]\right\}
\end{gathered}
$$

Edge impedance of the antenna can be found out by

$$
\begin{aligned}
& G_{1}=\frac{1}{90}\left(\frac{\omega}{\lambda_{0}}\right)^{2} \\
& R_{\text {in }}=\frac{1}{2 G_{1}}
\end{aligned}
$$


Where $R_{\text {in }}=$ edge impedance, $G_{1}=$ transconductance of patch, $\mathrm{W}=$ width of patch, $\lambda_{0}=$ free space wavelength [9]. Quarter wave transformer impedance can be found out by,

$$
Z_{q}=\sqrt{R_{\text {in }} Z_{0}}
$$

Length of quarter wave transformer is quarter of wavelength which

$$
\begin{gathered}
L_{1}=\frac{\lambda_{g}}{4} \\
\lambda_{g}=\frac{\lambda_{0}}{\sqrt{\varepsilon_{\text {reff }}}}
\end{gathered}
$$

As can be calculated width of quarter wave transformer as shown below [10]:

$$
\begin{gathered}
A=\frac{Z_{q}}{60} \sqrt{\frac{\varepsilon_{r}+1}{2}}+\frac{\varepsilon_{r}-1}{\varepsilon_{r}+1}\left(0.23+\frac{0.11}{\varepsilon_{r}}\right) \\
\frac{W_{1}}{h}=\frac{8 e^{A}}{e^{2 A}-2}
\end{gathered}
$$

As described in (1) to (4) physical parameters of patch antenna at $28 \mathrm{GHz}$ are listed in Table I.

TABLE I. PATCH DIMENSIONS FOR 28 GHZ ANTENNA

\begin{tabular}{|l|l|l|l|l|l|}
\hline $\mathbf{W}$ & $4.22 \mathrm{~mm}$ & $\mathbf{L}$ & $3.27 \mathrm{~mm}$ & $\mathbf{W}_{\mathbf{1}}$ & $0.24 \mathrm{~mm}$ \\
\hline $\boldsymbol{\varepsilon}_{\boldsymbol{r} \text { eff }}$ & 1.986 & $\boldsymbol{W}_{\mathbf{2}}$ & $1.5 \mathrm{~mm}$ & $\mathbf{Z}_{\mathbf{q}}$ & $119.93 \Omega$ \\
\hline $\boldsymbol{\Delta} \mathbf{L}$ & $0.257 \mathrm{~mm}$ & Sub_L & $8.27 \mathrm{~mm}$ & $\mathbf{R}_{\text {in }}$ & $287.68 \Omega$ \\
\hline $\mathbf{L}_{\mathbf{1}}$ & $1.94 \mathrm{~mm}$ & $\mathbf{L}_{\mathbf{2}}$ & $3 \mathrm{~mm}$ & Sub_W & $8.22 \mathrm{~mm}$ \\
\hline
\end{tabular}

Where Sub_L= length of substrate, Sub_W= width of substrate. Geometry of single element is shown in the Fig. 1.

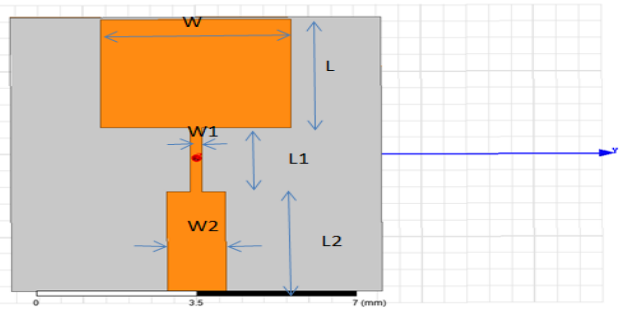

Fig. 1. Geometry of Single Element antenna at $28 \mathrm{GHz}$

\section{Design and Analysis of Two Elements Array}

Corporate feeding method is chosen to feed the array elements. In that type of configuration two-way power divider is used which divides $50 \Omega$ feed line into $100 \Omega$ feed lines as depicted in Fig. 2. Quarter wave transformers $(119.93 \Omega)$ are used to match the $100 \Omega$ lines to the edge impedance (287.68 $\Omega$ ). Geometry of two elements array is shown in the Fig. 2.

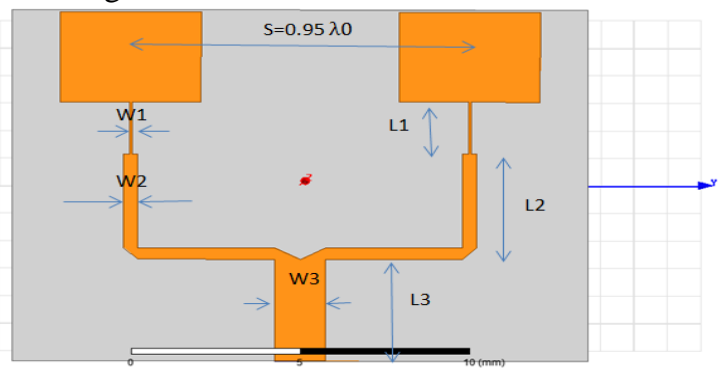

Fig. 2. Geometry of two elements array antenna at $28 \mathrm{GHz}$.

After Calculations, it can be shown width and length of the strip lines for different impedances by equations (5) and (9) as well as the other parameters in Table II.

TABLE II. DIMENSIONS OF TWO ELEMENTS ARRAY ANTENNA

\begin{tabular}{|l|l|l|l|l|l|}
\hline $\mathbf{W}$ & $4.22 \mathrm{~mm}$ & Sub_L & $12.77 \mathrm{~mm}$ & $\boldsymbol{L}_{\mathbf{3}}$ & $3.7 \mathrm{~mm}$ \\
\hline $\boldsymbol{W}_{\mathbf{1}}$ & $0.08 \mathrm{~mm}$ & $\boldsymbol{L}$ & $3.27 \mathrm{~mm}$ & Sub_W & $17.22 \mathrm{~mm}$ \\
\hline $\boldsymbol{W}_{\mathbf{2}}$ & $0.41 \mathrm{~mm}$ & $\boldsymbol{L}_{\mathbf{1}}$ & $1.89 \mathrm{~mm}$ & & \\
\hline $\boldsymbol{W}_{\mathbf{3}}$ & $1.5 \mathrm{~mm}$ & $\boldsymbol{L}_{\mathbf{2}}$ & $3.82 \mathrm{~mm}$ & & \\
\hline
\end{tabular}

\section{7ए' HMJQDQGS QDOVVIRI) RXU Elements Array}

In that configuration two-way power divider is used which divides $50 \Omega$ feed line into $100 \Omega$ feed lines, and another is used which divides $100 \Omega$ feed line into $200 \Omega$ feed lines, $239.86 \Omega$ quarter wave transformers are used to match the $200 \Omega$ lines to the edge impedance $(287.68 \Omega)$ as depicted in Fig. 3. Geometry of four elements is shown in the Fig. 3.

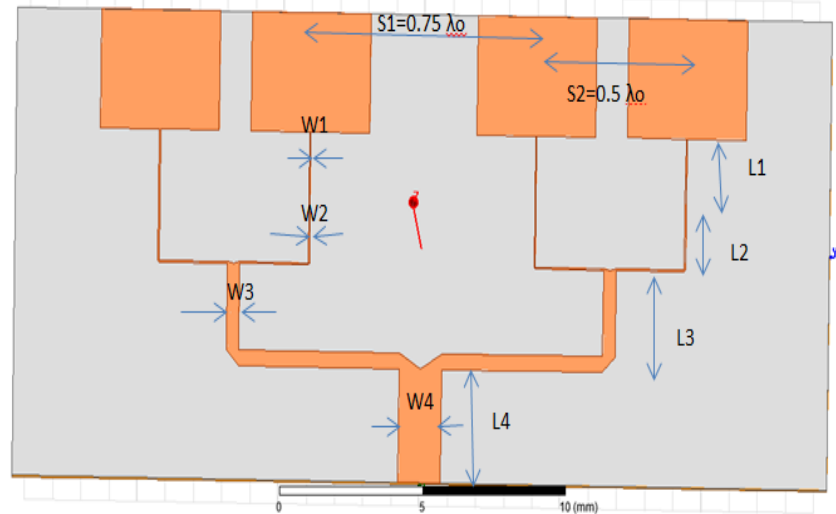

Fig. 3. Geometry of four elements array antenna at $28 \mathrm{GHz}$.

Table III shows dimensions of the four elements microstrip array antenna using the previous equations.

TABLE III. DIMENSIONS OF FOUR ELEMENTS ARRAY ANTENNA

\begin{tabular}{|l|l|l|l|l|l|}
\hline $\mathbf{W}$ & $4.22 \mathrm{~mm}$ & $\boldsymbol{W}_{\mathbf{4}}$ & $1.5 \mathrm{~mm}$ & $\boldsymbol{L}_{\mathbf{2}}$ & $1.74 \mathrm{~mm}$ \\
\hline $\boldsymbol{W}_{\mathbf{1}}$ & $0.046 \mathrm{~mm}$ & Sub_L & $12.80 \mathrm{~mm}$ & $\boldsymbol{L}_{\mathbf{3}}$ & $2.8 \mathrm{~mm}$ \\
\hline $\boldsymbol{W}_{\mathbf{2}}$ & $0.051 \mathrm{~mm}$ & $\boldsymbol{L}$ & $3.27 \mathrm{~mm}$ & $\boldsymbol{L}_{\mathbf{4}}$ & $3.1 \mathrm{~mm}$ \\
\hline $\boldsymbol{W}_{\mathbf{3}}$ & $0.438 \mathrm{~mm}$ & $\boldsymbol{L}_{\mathbf{1}}$ & $1.89 \mathrm{~mm}$ & Sub_W & $28.91 \mathrm{~mm}$ \\
\hline
\end{tabular}

\section{Q. Design and Analysis of Eight Elements Array}

In this method two-way power divider is used which divides $50 \Omega$ feed line into $100 \Omega$ feed lines, $70.7 \Omega$ quarter wave transformers are used to match the $100 \Omega$ feed lines to $50 \Omega$ feed lines, then another power divider is used which divides $50 \Omega$ feed line into $100 \Omega$ feed lines and another is used which divides $100 \Omega$ feed line into $200 \Omega$ feed lines. Finally, $239.86 \Omega$ quarter wave transformers are used to match the $200 \Omega$ lines to the edge impedance $(287.68 \Omega)$ as depicted in Fig. 4.

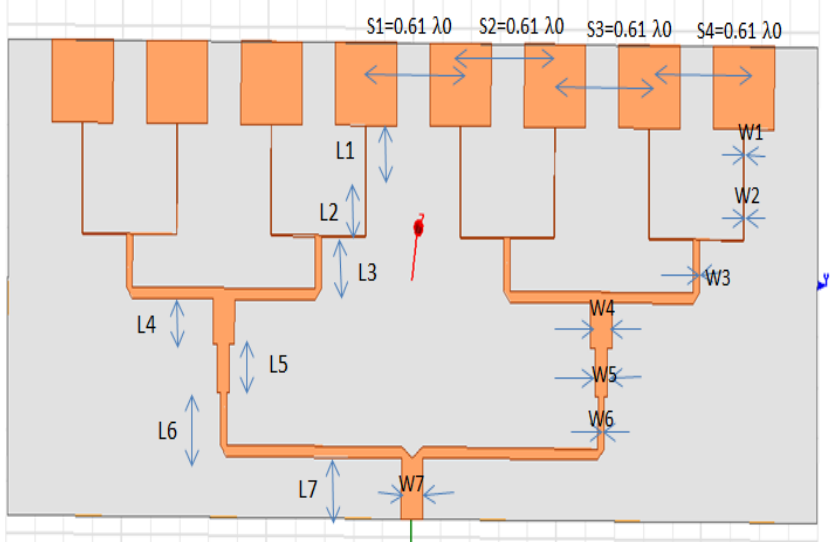

Fig. 4. Geometry of eight elements array antenna at $28 \mathrm{GHz}$.

Table IV shows dimensions of the eight elements microstrip array antenna using the previous equations. 
TABLE IV. DIMENSIONS OF EIGHT ELEMENTS ARRAY ANTENNA

\begin{tabular}{|l|l|l|l|l|l|}
\hline $\mathbf{W}$ & $4.22 \mathrm{~mm}$ & $\boldsymbol{W}_{\mathbf{4}}$ & $1.5 \mathrm{~mm}$ & Sub_L & $18.735 \mathrm{~mm}$ \\
\hline $\boldsymbol{W}_{\mathbf{1}}$ & $0.046 \mathrm{~mm}$ & $\boldsymbol{W}_{\mathbf{5}}$ & $0.84 \mathrm{~mm}$ & $\boldsymbol{L}$ & $3.27 \mathrm{~mm}$ \\
\hline $\boldsymbol{W}_{\mathbf{2}}$ & $0.053 \mathrm{~mm}$ & $\boldsymbol{W}_{\mathbf{6}}$ & $0.438 \mathrm{~mm}$ & $\boldsymbol{L}_{\mathbf{1}}$ & $1.89 \mathrm{~mm}$ \\
\hline $\boldsymbol{W}_{\mathbf{3}}$ & $0.438 \mathrm{~mm}$ & $\boldsymbol{W}_{\mathbf{7}}$ & $1.5 \mathrm{~mm}$ & $\boldsymbol{L}_{\mathbf{2}}$ & $2.5 \mathrm{~mm}$ \\
\hline $\boldsymbol{L}_{\mathbf{3}}$ & $2.5 \mathrm{~mm}$ & $\boldsymbol{L}_{\mathbf{5}}$ & $1.89 \mathrm{~mm}$ & $\boldsymbol{L}_{\mathbf{7}}$ & $2.4 \mathrm{~mm}$ \\
\hline $\boldsymbol{L}_{\mathbf{4}}$ & $1.78 \mathrm{~mm}$ & $\boldsymbol{L}_{\mathbf{6}}$ & $2.5 \mathrm{~mm}$ & Sub_W & $55.82 \mathrm{~mm}$ \\
\hline
\end{tabular}

\section{Results and Discussions}

\section{प.1. Single Element Patch Antenna}

From Fig. 5, single element patch antenna is resonates at $28 \mathrm{GHz}$ and having a return loss of $-31.96 \mathrm{~dB}$. Impedance bandwidth is $1.029 \mathrm{GHz}(27.5098 \mathrm{GHz}-28.539 \mathrm{GHz})$ and $\%$ Bandwidth of $3.67 \%$.

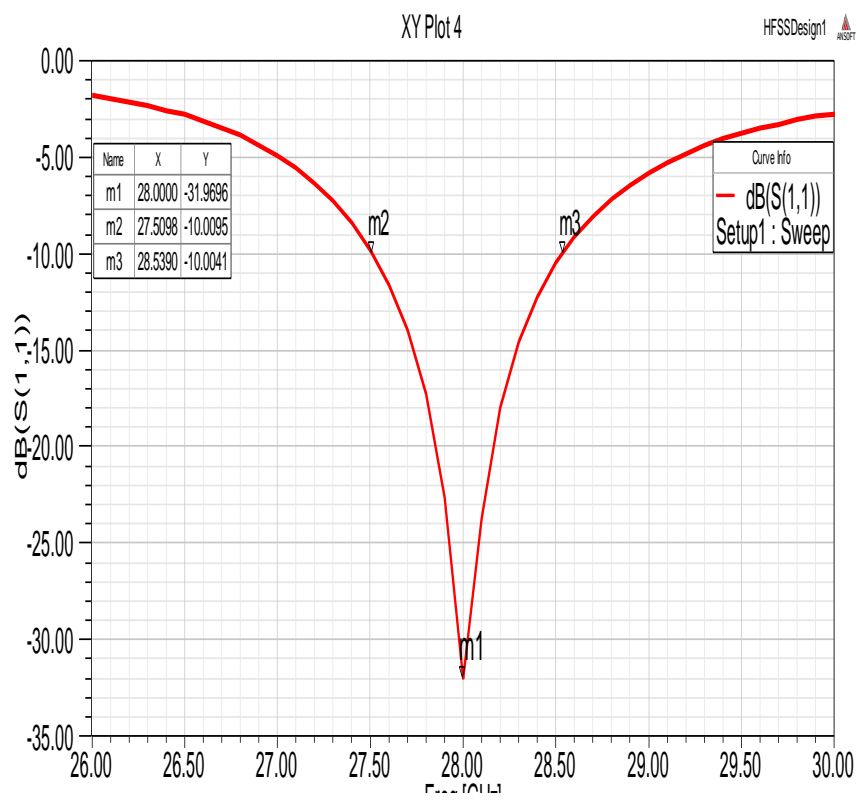

Fig. 5. S11 Parameter for $28 \mathrm{GHz}$ single element antenna.

Fig. 6 and Fig. 7 show the gain of $8.04 \mathrm{~dB}$ and directivity of $8.14 \mathrm{~dB}$, consquently, radiation efficiency is $97.7 \%$.

Radiation pattern of E-plane and $\mathrm{H}$-plane at $28 \mathrm{GHz}$ are shown in Fig. 6. Half power beam width is $57.58^{\circ}$ for $\mathrm{H}$-plane and $74^{\circ}$ for E-plane.

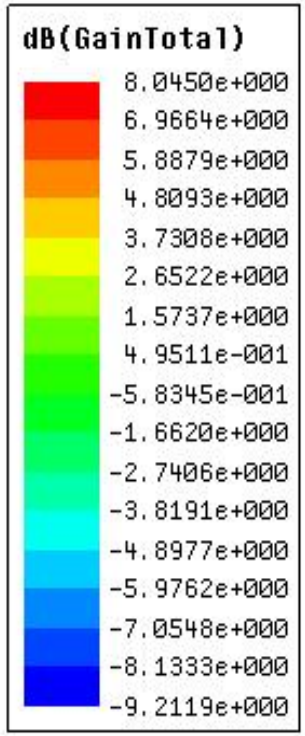

Fig. 6. 3D polar plot for gain of single element antenna.

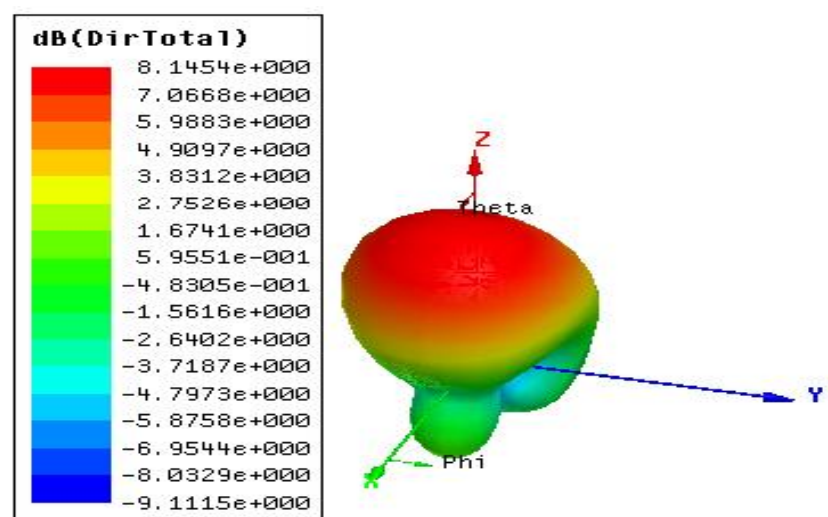

Fig. 7. 3D polar plot for directivity of single element antenna.

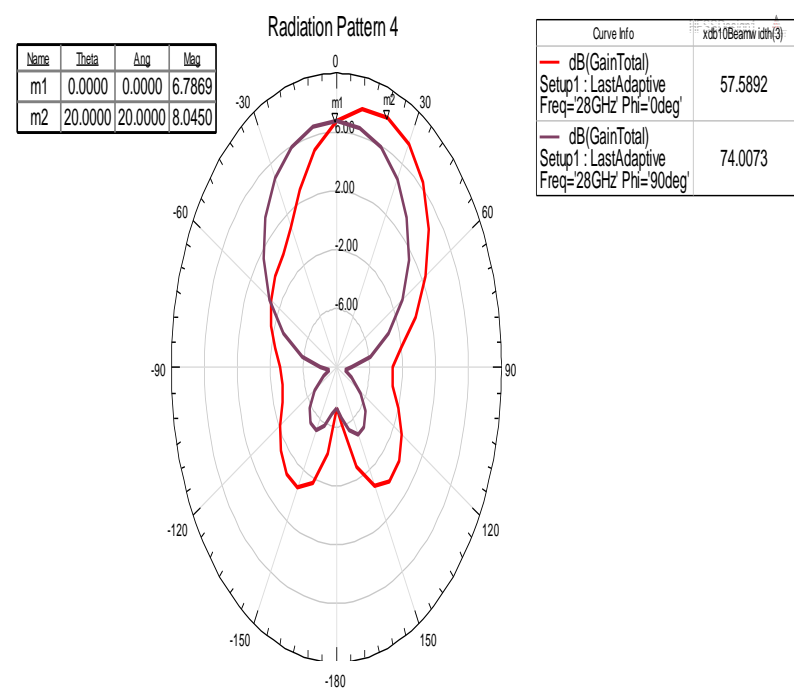

Fig. 8. Radiation pattern of single element antenna.

\section{प.2. Two Elements Patch Array Antenna}

Two elements array antenna has less return loss of $19.27 \mathrm{~dB}$ as shown in Fig. 9. Also, impedance bandwidth is 1.488 $\mathrm{GHz}(27.173 \mathrm{GHz}-28.661 \mathrm{GHz})$ and \% Bandwidth of $5.31 \%$.

This antenna has $11.05 \mathrm{~dB} \& 11.26 \mathrm{~dB}$ gain and directivity respectively as shown in Fig. 10 and Fig. 11. It can be concluded radiation efficiency is $95.33 \%$. Fig. 12 illustrates radiation pattern of E-plane and $\mathrm{H}$-plane. It shows half power beam width is $50.7^{0}$ for $\mathrm{H}$-plane and $29.88^{\circ}$ for E-plane.

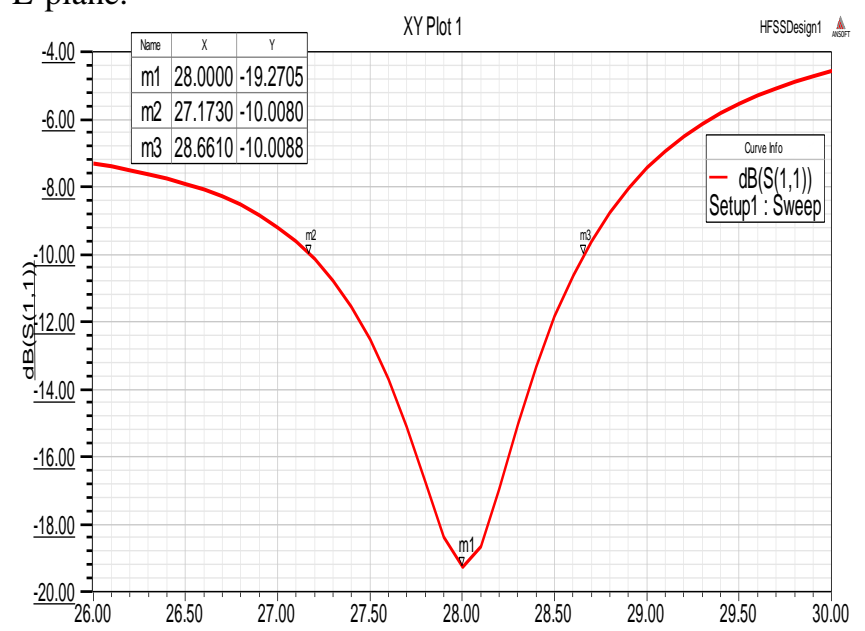

Fig. 9. S11 Parameter for two elements array antenna. 


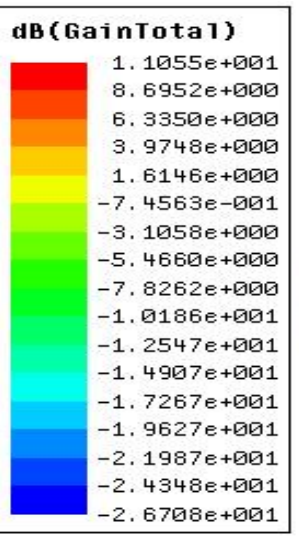

Fig. 10. 3D polar plot for gain of two elements array antenna.
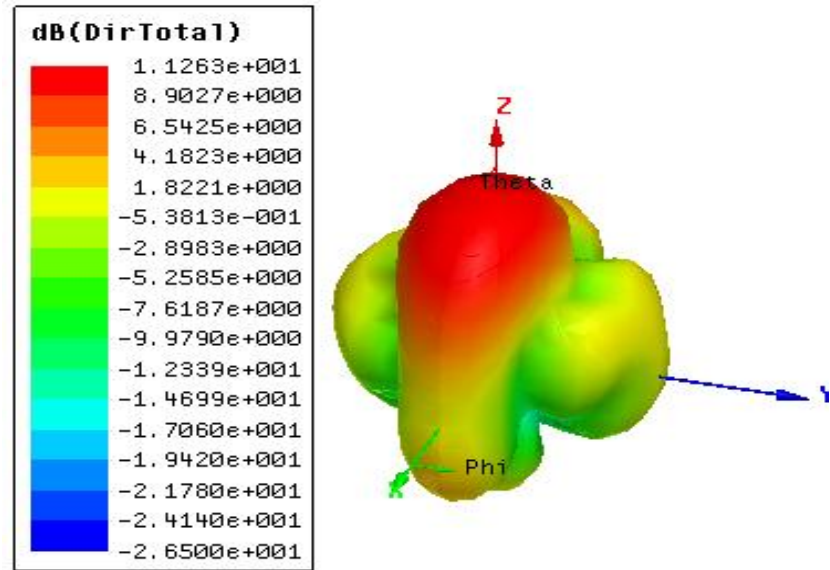

Fig. 11. 3D polar plot for directivity of two elements array antenna

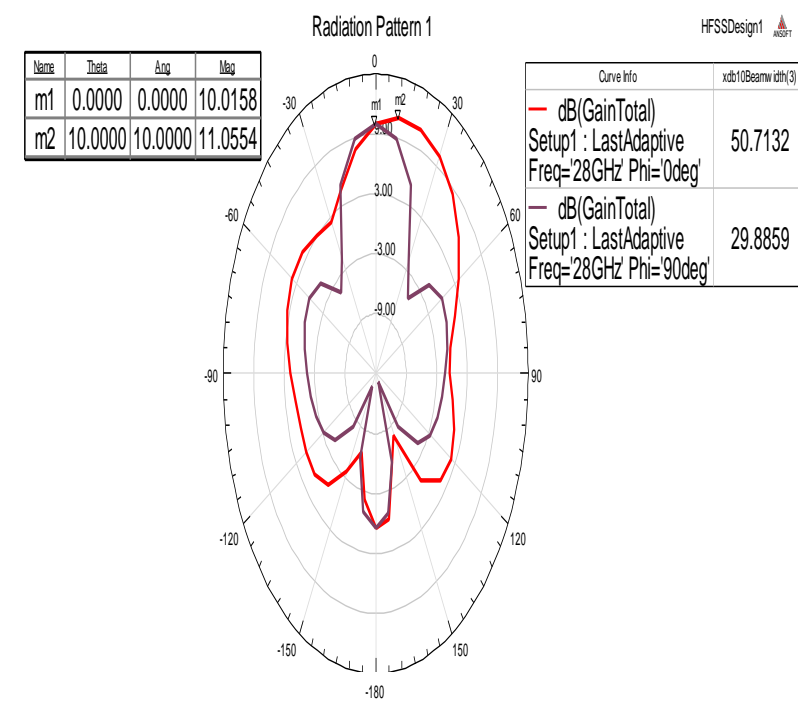

Fig. 12. Radiation pattern of two elements array antenna.

\section{प.3. Four Elements Patch Array Antenna}

It can be noted return loss decreases to $-18.8 \mathrm{~dB}$ in four elements array antenna as seen in Fig. 13. In the opposite, impedance bandwidth increseses to $1.99 \mathrm{GHz}(26.855 \mathrm{GHz}$ $-28.845 \mathrm{GHz}$ ) and \% Bandwidth of $7.11 \%$.

As expected the gain of this antenna increases to $13 \mathrm{~dB}$ and directivity up to $13.11 \mathrm{~dB}$ as shown in Fig.14 and Fig. 15, so the radiation efficiency is still high of $97.46 \%$.

Fig. 16 shows radiation pattern of E-plane and H-plane. It illustrates half power beam width is $39.09^{\circ}$ for $\mathrm{H}$-plane and $19.91^{0}$ for E-plane.

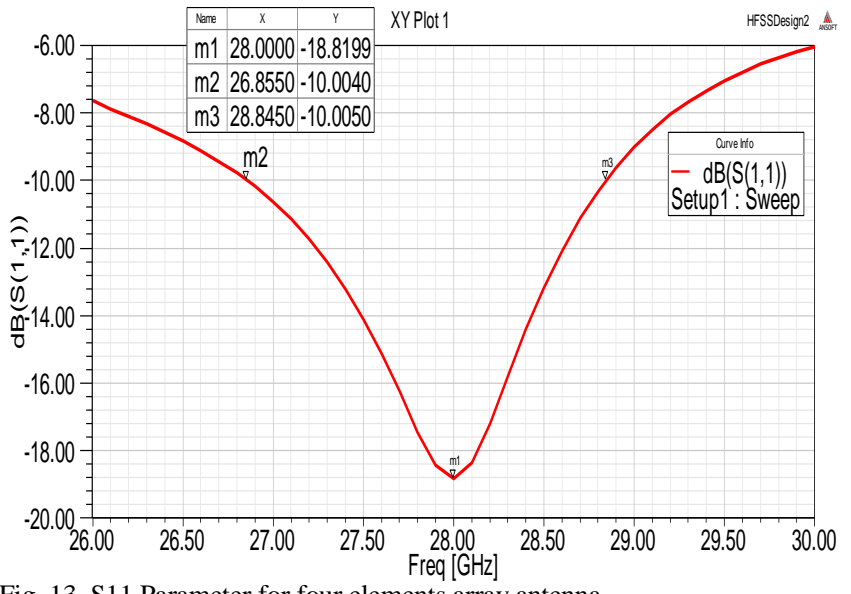

Fig. 13. S11 Parameter for four elements array antenna.

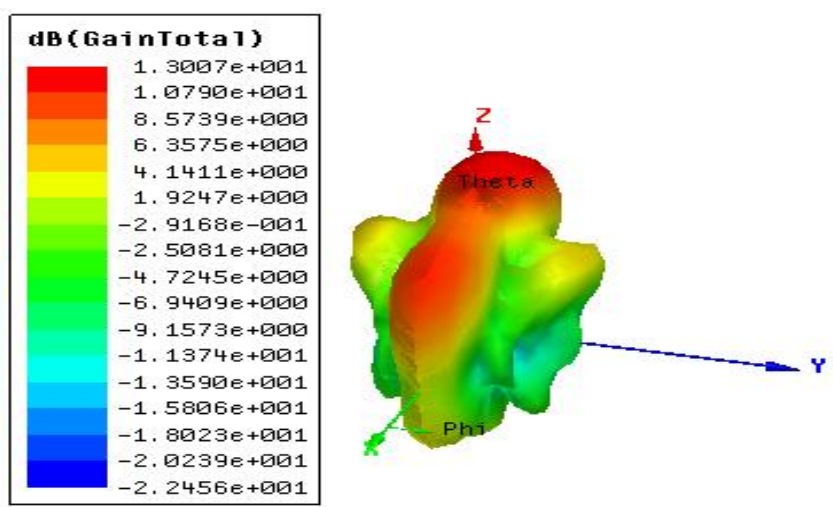

Fig. 14. 3D polar plot for gain of four elements array antenna.

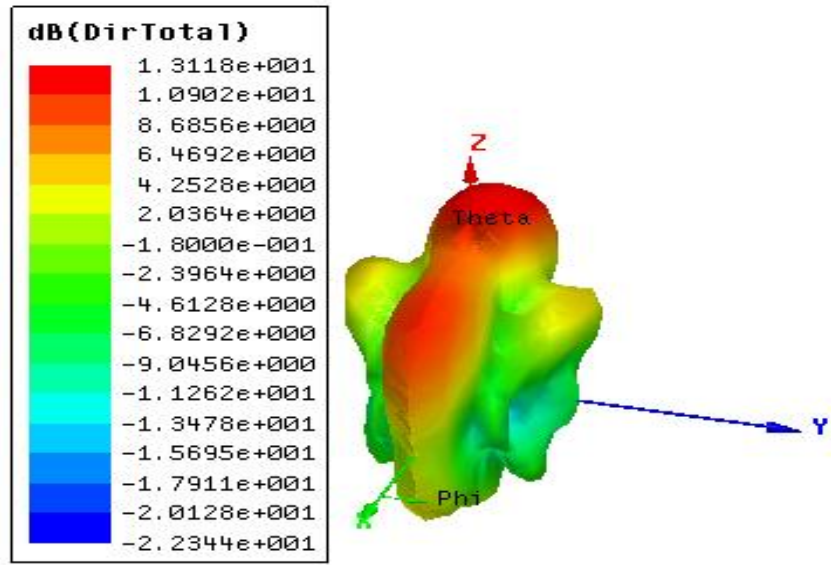

Fig. 15. 3D polar plot for gain of four elements array antenna.

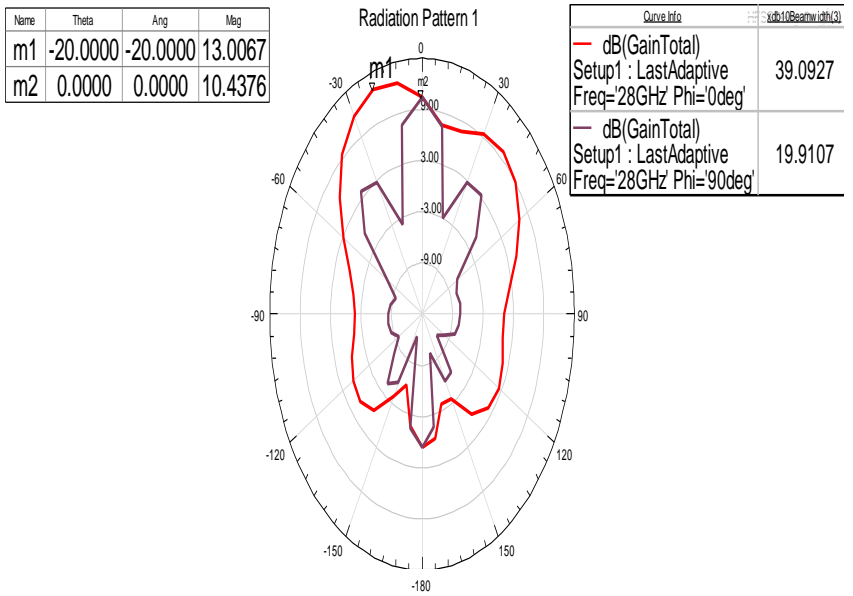

Fig. 16. Radiation pattern of four elements array antenna. 


\section{प.4. Eight Elements Patch Array Antenna}

It can be noted return loss is the best than the previous antennas, it is $-36.7 \mathrm{~dB}$ as seen in Fig. 17. Impedance bandwidth increases to $2.56 \mathrm{GHz}(26.094 \mathrm{GHz}-28.65 \mathrm{GHz})$ and $\%$ Bandwidth of $9.13 \%$.

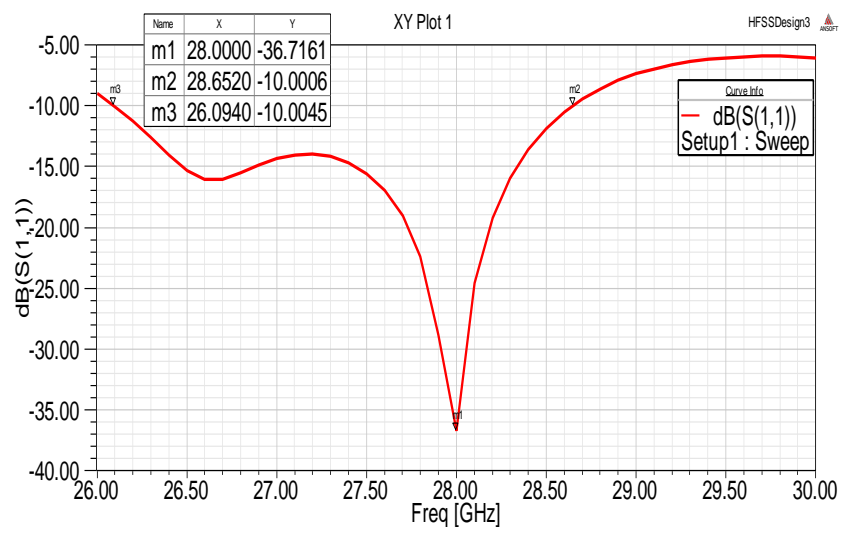

Fig. 17. S11 Parameter for eight elements array antenna.

The gain of this antenna increases to $15.69 \mathrm{~dB}$ and directivity up to $15.96 \mathrm{~dB}$ as shown in Fig. 18 and Fig. 19, so the radiation efficiency is $93.95 \%$.

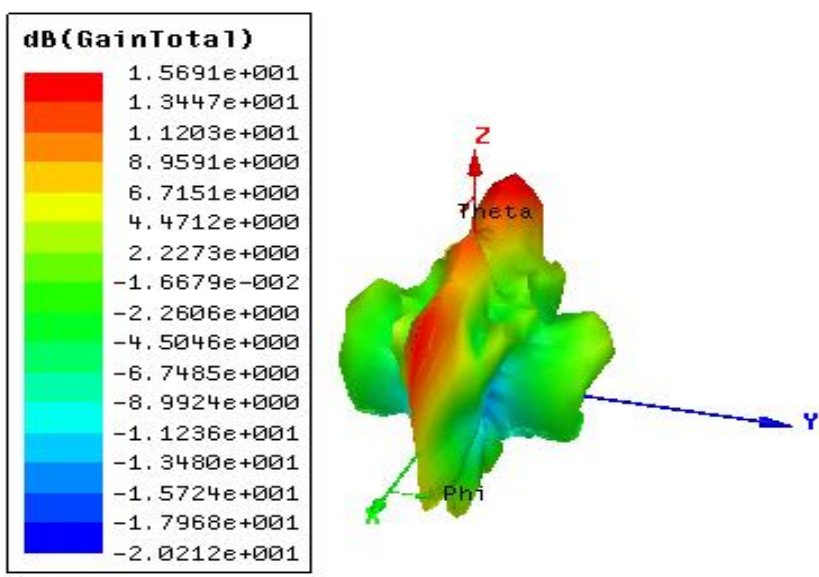

Fig. 18. 3D polar plot for gain of eight elements array antenna.

Fig. 20 shows radiation pattern of E-plane and H-plane. It can be concluded half power beam width is $27.62^{\circ}$ for $\mathrm{H}$-plane and $4.82^{\circ}$ for E-plane. As can be noted H-plane is better than E-plane in terms of gain, in other words, the maximum gain for eight elements array antenna in $\mathrm{H}$-plane is $9.97 \mathrm{~dB}$, in the opposite, the maximum gain in $\mathrm{E}$-plane is $9.97 \mathrm{~dB}$ only.
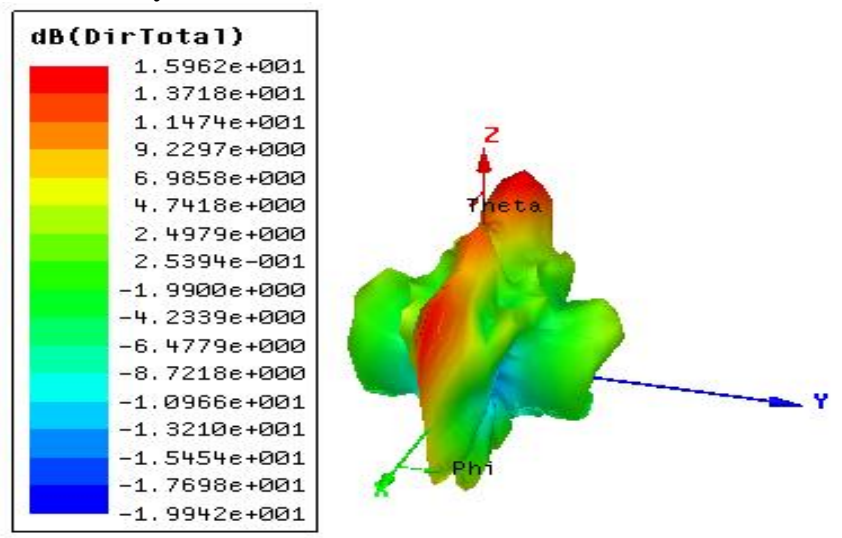

Fig. 19. 3D polar plot for directivity of eight elements array antenna.

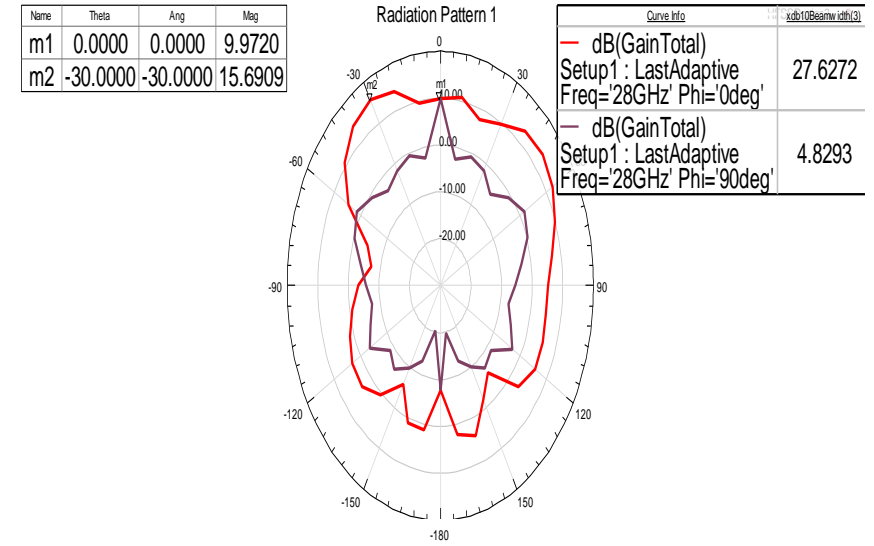

Fig. 20. Radiation pattern of eight elements array antenna.

\section{Conclusion}

In this study, Single element antenna, two elements array and four elements array with optimized separation are designed and analyzed. For an array antenna with a number of patch elements result in improvement of Gain, Bandwidth as well as Directivity. Separation between two elements performs major role in antenna performance. Additionally Cut slots in the feed line can also improve the power radiating capability and improve the performance. It is observed that the Single element antenna achieves the gain of $8.04 \mathrm{~dB}$ with the Bandwidth of $1.03 \mathrm{GHz}$, two elements array antenna achieves the gain of $11.05 \mathrm{~dB}$ with the bandwidth of $1.49 \mathrm{GHz}$, four elements array antenna has bandwidth as $1.99 \mathrm{GHz}$ and gain of $13 \mathrm{~dB}$, eight elements array antenna has maximum bandwidth as $2.56 \mathrm{GHz}$ and high gain of $15.69 \mathrm{~dB}$. All presented antennas are good competitors for future $5 \mathrm{G}$ Communications.

\section{References}

[1] Mohamed H. Abusaada, "Design of efficientmillimeter wave planar antennas for $5 \mathrm{G}$ communication systems," The Islamic UniversityGaza, April, 2017.

[2] Janam Mahrjan, Dong-you Choi, "Four element microstrip patch array antenna withcorporate series feed network for 5G communication," International journal of antenna and propagation, 2020.

[3] Janam Mahrjan, Dong-you Choi, "Design of A 4.5 GHz Rectangular Microstrip Patch Antenna," International journal of trend in research and development, 2017.

[4] Gautam D. Makwana, Warren L. Stutzman, "Antenna theory and design ," John Wiely\& sons, inc, second edition,1998.

[5] KiranKumar A. Solanki, Gautam D. Makwana, "Study and analysis of microstrip patch array antenna at $12 \mathrm{GHz}$ for $5 \mathrm{G}$ applications," Journal of remote sensing GIS \& technology, 2018.

[6] Akaninyene B. Obot1, Gabriel A. Igwue, and Kufre M. Udofia, "Design and simulation of rectangular microstrip antenna arrays for improvedgain performance," International Journal of Networks and Communications, 2019.

[7] Mohanad F. Abdulhamid, Waihenya Ndung, "on the design of patch antenna array,” Technology engineering, 2019.

[8] Mohammed Abu Saada, Talal Skaik, and Ramadan Alhalabi, "Design of efficient microstrip linear antenna array for 5G communication system," 2019.

[9] Hamza A. Saoud, Abdelgader Z. Abdalla, "Design and simulation of rectangular microstrip antenna array for improve gain operate at ku band for satellite application," college of electronic technology, Bani-Walid, Libya, 2020.

[10] Abdullahi Ayegba, Wysenyuy Desmond Fonyuy, and Ihiabe Yakubu Adejoh, "Design of A $4.5 \mathrm{GHz}$ rectangular microstrip patch antenna," International journal of trend in research and development, 2017. 


\section{Creative Commons Attribution License 4.0} (Attribution 4.0 International, CC BY 4.0)

This article is published under the terms of the Creative Commons Attribution License 4.0

https://creativecommons.org/licenses/by/4.0/deed.en_US 